\title{
EL PUNTO DE PARTIDA DE LA FILOSOFIA
}

\author{
Antonio González, S. J.*
}

"Der Mut der Wahrheit ist die erste Bedingung der Philosophie" (Hegel)

\section{Planteamiento del problema.}

T a filosofía contemporánea presenta, en cierta medida, un paLnorama que podríamos denominar escolástico. Ciertamente, los términos "escolástico" y "metafísico", constituyen las denominaciones más usuales de lo que la mayor parte de los filósofos actuales no quisieran ser. Y no cabe duda de que, en cierto sentido, pocos pensadores hoy vivientes son escolásticos, si por escolástica se entiende el pensamiento aristótélico en su interpretación tomista. Si la escolástica designa solamente una determinada escuela filosófica, no cabe duda de que esta escuela está poco representada en el campo de los filósofos actuales. Sin embargo, el término "escolástica" no designaba originariamente una determinada escuela de filósofos, sino más bien un modo espúreo de filosofar. Y este modo de filosofar sí está presente, incluso demasiado presente, en la actualidad.

Filosofar de un modo escolástico no significa, primariamente, ser aristotélico o ser tomista. Filosofar de modo escolástico signifi-

* Jefe del Departamento de Filosofía de la UCA. 
ca hacer de la filosofía una tarea de escuela. $Y$, al hacer de la filosofía una tarea de escuela, la filosofía deja de ser un auténtico filosofar, para convertirse solamente en una caricatura del mismo. Hacer de la filosofía una tarea de escuela no significa necesariamente repetir mecánicamente el pensamiento de unos determinados maestros. En realidad, la escolástica aristotélico-tomista fue en ocasiones muy crítica de Aristóteles y de santo Tomás. Lo característico del pensar escolástico no es tampoco que se utilicen argumentos de autoridad. Ciertamente, este tipo de argumentación se ha utilizado no solamente en la escolástica aristotélico-tomista, sino también en la escolástica marxista y en otras muchas escolásticas: la cita de las sagradas escrituras de un padre fundador era suficiente para fundamentar una proposición. Ahora bien, se puede ser escolástico prescindiendo de toda autoridad, e incluso negándola explícitamente. El modo de pensar escolástico es más sutil, y no se deja fácilmente encerrar en las caricaturas fáciles.

Hacer filosofía escolástica es algo más grave y más radical. Consiste proclamarse filósofo sin haberse preocupado nunca de haber justificado el propio punto de partida. Así se nos dice con toda alegría, por ejemplo, que lo propio de la filosofía contemporánea es y tiene que ser la reflexión sobre el lenguaje. Es una afirmación con la que la filosofía analítica, la filosofía hermenéutica y, tal vez, otras escuelas contemporáneas pueden sentirse muy a gusto. Es perfectamente posible entender por qué históricamente en el ámbito del neopositivismo surgió un gran interés por el lenguaje cotidiano. Esto es muy interesante para la historia de la filosofía, pero todavía no constituye una fundamentación suficientemente rigurosa de por qué el punto de partida de la filosofía tiene que ser precisamente el análisis del lenguaje. Comenzar a hacer una filosofía del lenguaje sin justificar radicalmente el punto de partida o diciendo a lo sumo que éste es el punto de partida de muchas escuelas contemporáneas, es un modo de proceder perfectamente escolástico.

En este sentido concreto, la mayor parte de lo que se vende actualmente como filosofía tiene un carácter de escuela. Tenemos escolásticas neopositivistas, analíticas, hegelianas, marxistas, francfortianas, nietzschenas, kantianas, fenomenológicas, existencialistas, zubirianas y todo un largo etcétera de sus posibles 
combinaciones. El problema no está en que cada una de estas escuelas enuncie o puieda enunciar grandes e importantes verdades. El problema está en que ellas no emprenden una justificación radical del propio punto de partida. Cuando las discusiones filosóficas se ponen interesantes, es decir, cuando los pensadores tienen que justificar sus conceptos fundamentales, lo más frecuente es contentarse con la lánguida constantación de que, en definitiva, cada uno proviene de diferentes tradiciones de pensamiento. Es como si los filósofos actuales fueran, en el fondo de su corazón, verdaderos hermeneutas, pues pareciera que es una determinada tradición lo que últimamente justifica su filosofía. Y, en realidad, solamente la filosofía hermenéutica reflexiona explícita y sistemáticamente sobre sus presupuestos para decirnos que, de hecho, no es posible pensar sin prejuicios, sin pertenecer a una escuela o a una tradición1.

La hermenéutica es, por esto, la canonización del modo escolástico de hacer filosofía. Sin embargo, esta canonización es, en sí misma, también escolástica. La hermenéutica no demuestra nunca, ni intenta demostrar, que no sea posible un punto de partida radical en la filosofía. Solamente nos recuerda que los puntos de partida que se han propuesto históricamente tenían ciertos presupuestos. Hasta aquí, la hermenéutica es filosofía auténtica y radical. Sin embargo, en lugar de desprenderse de los presupuestos del pasado para proponer renovadamente un punto de partida más radical, la hermenéutica se ahorra el esfuerzo del pensamiento para decirnos cómodamente que toda filosofía se mueve en una tradición. El problema es que, en este mismo instante, la filosofía deja de ser auténtica filosofía para convertirse en un triste comentario histórico o cultural. La filosofía auténtica aparece allí donde los propios presupuestos, lejos de ser aceptados sin más, se somenten a una crítica radical, sea para justificarlos de un modo contundente, sea para eliminarlos, determinando en cuaquiera de los dos casos un punto de partida auténtico para el filosofar.

Esta justificación radical de los propios presupuestos no elimina en modo alguno la historicidad. Al contrario. La justificación del propio punto de partida parte de la convicción de que los puntos de partida que históricamente se han propuesto en filosofía estaban lastrados con presupuestos no cuestionados. La elimi- 
nación de estos presupuestos del pasado es una condición inexorable para la justificación de un nuevo punto de partida. Del mismo modo, si esta justificación es suficientemente crítica, admitirá la posibilidad de que su propuesta contenga también presupuestos que en el futuro se puedan suprimir. Esa supresión, lejos de eliminar la necesidad de justificar el propio punto de partida, es más bien una confirmación de que la filosofía, la auténtica filosofía, lejos de ser una tarea de escuela, es ciertamente una tarea históricamente abierta, pero es también una tarea absolutamente crítica de perenne radicalización. Entonces es cuando la filosofía deja de ser escolástica para ser auténtico filosofar. $Y$ este filosofar, y no una determinada escuela filosófica, es lo que constituye la verdadera philosophia perennis.

\section{La relevancia de la tarea}

F $n$ el llamado Tercer Mundo se plantea con frecuencia la nece¿sidad urgente de un auténtico filosofar ${ }^{2}$. Es decir, aparece una conciencia creciente de que las filosofías usuales han nacido para responder a los problemas propios de otros contextos. Caben sin duda las adaptaciones locales, muchas de ellas brillantes y operativas. Sin embargo, se puede también sospechar que estos esfuerzos no constituyen un auténtico filosofar porque, en cuanto adaptaciones, no llevan a cabo la reflexión crítica sobre los presupuestos de las filosofías adaptadas. $\mathrm{Y}$ muchas veces son precisamente estos presupuestos los que de un modo más eminente reflejan el contexto en el que han surgido las distintas filosofías. Entonces no basta decir que esas filosofías, una vez adaptadas, son útiles para enfrentar los problemas del Tercer Mundo. Porque puede ser que, tras la aparente utilidad, se escondan precisamente aquellos presupuestos que, directa o indirectamente, han presidido y legitimado la conquista, sometimiento y explotación de la mayor parte de la población mundial.

Es bien sabido que la dominación europea del mundo ha recurrido, por ejemplo, a una idea excluyente de la racionalidad, identificada unilateralmente con la razón científica moderna. A esto se podrían añadir, solamente a modo de ejemplos, la concepción individualista de la realidad humana, la visión unilineal de la historia, o también la negación de la alteridad en un pensamiento con 
voluntad totalizadora. Se trata de presupuestos de los que parten muchas escuelas filosóficas sin ser nunca sometidos a crítica o a justificación. Y aquí no basta con decir que en ciertas escuelas filosóficas occidentales estos presupuestos ya han sido criticados. Esto es muy cierto e importante para toda filosofía con vocación liberadora. Pero la crítica de esos presupuestos no es ninguna garantía de que en esas escuelas no sobrevivan otros prejuicios mucho más eficaces ideológicamente. Por eso mismo, una filosofía liberadora no puede ser solamente la aplicación ética o política de cualquier escuela filosófica ya constituida. Una filosofía liberadora tiene que ser, necesariamente, un auténtico filosofar. Y esto significa la necesidad someter a crítica los propios presupuestos para justificar radicalmente el propio punto de partida.

Con esto, el auténtico filosofar confluye naturalmente con el deseo de hacer una filosofía original y con la aspiración de que este filosofar original sea liberador. Hacer una filosofía original no es, primariamente, elaborar una reflexión sobre la cultura de una determinada región del mundo. Esto es sin duda un tema importante para la incardinación de toda filosofía. Sin embargo, no es lo que la constituye como filosofía ni es tampoco lo que garantiza su autonomía respecto a las escuelas filosóficas. Se puede filosofar sobre una cultura local sin abandonar los presupuestos hermenéuticos, neokantianos o hegelianos. La verdadera originalidad filosófica no reside en lo novedoso de un tema, sino en la radicalidad de su punto de partida3. Y el que esa filosofía sea liberadora no depende de sus buenas intenciones o de sus temas de interés. Todo esto es, sin duda, muy importante. Pero no por hablar de la liberación se hace algo liberador, como bien sabe todo el que ha conocido el uso ideológico de doctrinas inicialmente emancipadoras. La más importante contribución liberadora de la filosofía está justamente en la eliminación de los prejuicios opresores que, por ser prejuicios, permanecen enquistados en la cultura, en la ciencia, y en las doctrinas filosóficas. $Y$, para hacer esto, tiene que justificar radicalmente un punto de partida libre de esos prejuicios. Es decir, tiene que ser un auténtico filosofar.

\section{El camino hacia el comienzo}

¿Cómo hallar este punto de partida radical para el filosofar? Se 
pueden intentar distintas vías para lograr esto. Se podría, por ejemplo, hacer una consideración general sobre la historia de la filosofía para ver cuáles han sido los grandes modos de plantear el punto de partida del filosofar, y presentar después una superación sintética de los mismos4. La dificultad de esta vía consiste en que difícilmente se puede hacer una teoría general de toda la historia de la filosofía sin que en ella vayan incluidos muchos presupuestos interpretativos de cada autor y de cada período. Una segunda vía podría consistir en un diálogo crítico con las ciencias, mostrando en ellas la presencia de muchos prejuicios filosóficos y, por tanto, la necesidad de recurrir a una reflexión propiamente filosófica para eliminar estos presupuestos desde un punto de partida radical5. La dificultad de esta segunda vía consiste en que ella simplemente nos remite a la necesidad de buscar filosóficamente un punto de partida radical. Pero no nos dice todavía cuál es ese punto, de modo que tal vía es útil para mostrar la relevancia de una filosofía radical para las ciencias mismas, pero no para determinar cuál es el punto de partida que buscamos. Ella nos deja simplemente ante un problema que no es científico, sino filosófico.

Por eso vamos a intentar aquí una vía distinta para determinar este punto de partida que buscamos. A esta vía la vamos a denominar "filosofía primera", no en el sentido que Aristóteles le dio a ese término, sino simplemente para designar la búsqueda filosófica de un punto de partida radical para el filosofar. Este punto de partida, por ser radical, tiene que estar libre de todo presupuesto no justificado. Será entonces un punto de partida absolutamente justificado, que se nos ha de imponer como una verdad firme y libre de toda duda. Ahora bien, sabemos sobradamente que todas las cosas pueden ponerse en duda, incluso la propia realidad o la realidad del mundo. Sin embargo, hay algo que no puedo poner en duda: el hecho mismo de dudar. Es lo que en la historia de la filosofía se ha llamado el cogito puedo dudar de todo, menos del acto mismo de dudar. Es una observación que ya se encuentra en san Agustín, y que recogen explícitamente Descartes y Husserl6. Naturalmente, aquí no partimos de san Agustín, Descartes o Husserl, sino del cogito como el punto de partida que, en cuanto indubitable, está absolutamente justificado.

Ahora bien, justamente a este punto de partida cartesiano se le 
ha acusado de estar cargado de los presupuestos subjetivistas, intelectualistas, e idealistas propios de la modernidad filosófica y, en general, de la civilización burguesa europea con sus afanes de dominación universal7. Entonces su aparente radicalidad no sería tal. En el cogito tendríamos, como presupuestos no sometidos a duda, la idea de que el ser humano consiste en subjetividad, la idea de que la actividad esencial de este sujeto es una actividad intelectiva, y la idea de que este sujeto con su actividad pensante está aislado de los demás sujetos y del mundo real, a los cuales habríamos de llegar por medio de algún tipo de razonamiento como los que intentó Descartes. En el cogito, en lugar de un punto de partida libre de presupuestos, habría más bien todo un cúmulo de prejuicios modernos y burgueses que lo harían inviable como punto de partida radical para el filosofar, especialmente para un filosofar que tenga unas intenciones liberadoras ${ }^{8}$.

En realidad, hay que reconocer que las mencionadas acusaciones contra las filosofías de Descartes y Husserl son, en su raíz, correctas. $Y$, sin embargo, es difícil negar la firmeza y la radicalidad de la argumentación que conduce al cogito: es posible dudar de casi todas las cosas, pero no es posible poner en duda el hecho mismo de dudar. En este aspecto, el cogito es inatacable. Sin embargo, sería un falso dilema el pensar que hay que optar entre cargar con todos los presupuestos del cogito o renunciar a un punto de partida verdaderamente radical. En ambos casos estaríamos renunciando, explícita o implícitamente, a la radicalidad propia de la filosofía. En el primer caso, la filosofía estaría condenada a ser una escolástica cartesiana o husserliana. En el segundo caso, se podría acabar aceptando cualquier otra escolástica filosófica en nombre del carácter inevitable de la "tradición". Pero el dilema es falso, porque cabe una tercera alternativa, que es la verdaderamente filosófica: eliminar los presupuestos que hay en el cogito, para ir más allá del mismo, radicalizando de este modo el punto de partida del filosofar.

Esto significa que al cogito le vamos a hacer una crítica interna, y no solamente externa o contextual. Es decir, no vamos a centrarnos aquí, por ejemplo, en la falta de una reflexión cartesiana o husserliana sobre la práctica9. Posiblemente se trata de un crítica muy acertada. Pero para que esta crítica sea verdaderamente filo- 
sófica, y no solamente moral, política o religiosa, es importante mostrar que esa falta de reflexión sobre la práctica no se debe solamente a presuntas deficiencias morales, políticas o religiosas del respectivo filósofo, sino a la falta de radicalidad en la eliminación de los presupuestos con los que están lastradas las formulaciones clásicas del cogito. Si solamente de las buenas intenciones se tratara, no se puede negar de modo alguno que Husserl entendió su filosofía como un servicio a una humanidad amenazada10. $\mathrm{Si}$ este servicio se quiere hacer filosóficamente más radical, hay que proceder como filósofos, y no como moralistas. $Y$ para ello tenemos que reflexionar sobre el punto de partida del filosofar. En realidad, como veremos, una radicalización filosófica del cogito nos va a llevar a un punto de partida que, lejos de ser ajeno a la práctica, se encuentra nada menos que en el núcleo de la misma.

\section{La crítica del subjetivismo}

tendamos al carácter subjetivista del cogito, pues en él se en-
cuentra la raíz de su individualismo y de su idealismo. Cuando Descartes formula su tamoso punto de partida, a reglón seguido nos dice que el punto de partida recién descubierto consiste en lo que él llama "una cosa que piensa". Y más adelante señala que esta cosa que piensa ha de ser concebida como una sustancial1. Por su parte, Husserl entiende que el cogito no puede reducirse a un mero torrente cático de impresiones, justamente porque tiene carácter consciente, y en esta conciencia es en lo que consiste la subjetividad12. En ambos casos ha tenido lugar un deslizamiento, prácticamente inadvertido, desde el cogito hacia el "yo" (ego) que cogita. En el caso de Descartes, este ego es concebido como sustancia. En el caso de Husserl, como subjetividad. Ahora bien, el punto de partida radical inicialmente descubierto no era el ego, sino el cogito: puedo dudar de todo, menos del hecho mismo de estar dudando. Este dudar, observémoslo bien, no es un ego, sino un acto de cogitar. Lo que aparece en el punto de partida no es un sujeto, sino el cogito del que no se puede dudar. Sin embargo, tanto Descartes como Husserl no centran su "filosofía primera" en el acto de cogitar, sino ante todo y sobre todo en el ego que cogita, al cual interpretan como sustancia pensante o como subjetividad consciente. 
En realidad, tanto la idea de "sustancia" (substantia) como la de "sujeto" (subjectum) tienen un origen etimologico muy semejante. En ambos casos, se trata de algo que "está" (stantia) "puesto" (jectum) bajo (sub) las propiedades que soporta. Ya el mismo Aristóteles pensaba que la sustancia (ousía) tiene fundamentalmente el carácter de sujeto o soporte (hypokeimenon) de accidentes o predicados. Y Descartes, a pesar de su radicalidad en la búsqueda de un nuevo punto de partida para la filosofia, es en realidad un heredero de la idea aristotélica de sustancia. Por eso pasa inmediatamente del cogito al presunto soporte del mismo. El cogito se convierte entonces en un modo o propiedad de el ego entendido como sustancia pensante, y en él se centra su filosofía. Del mismo modo, Husserl piensa que todo acto remite inmediatamente a un ego que lo ejecuta, interpretado ahora como "subjetividad". En ambos casos tenemos un presupuesto, que consiste en pensar que los actos (como el cogito) son simples predicados, propiedades o accidentes de una realidad que los soporta, de modo que el descubrimiento de ese acto significa de modo inmedito el descubrimiento de su soporte sustancial o subjetual.

Obviamente, aquí no estamos diciendo que no exista algo así como el "yo". Se trata simplemente de señalar que, contra lo que Descartes mismo creyó, la primera verdad por él descubierta no es un ego, sino un acto, el acto de cogitar. No se trata de un acto en sentido aristotélico, como actualización de unas potencias. Se trata del acto mismo en su simplicidad, prescindiendo de toda explicación metafísica del mismo en términos de potencias, facultades, capacidades o estructuras. De este acto no puedo dudar cuando dudo de todo lo demás. Naturalmente, después podré investigar cuál es el agente de este acto y en qué consiste su realidad. Pero lo que constituye un presupuesto injustificado es la sustitución del cogito por el ego, para convertir a este último en el punto de partida del filosofar. A este presupuesto se le añade la conceptuación de este ego como sustancia o como subjetividad. Con ello, se está aceptando subrepticiamente una visión sustratual (sustancialista o subjetivista) de la realidad. Curiosamente, a pesar de la radicalidad de Descartes y de Husserl, el aristotelismo ha quedado de alguna manera incrustado en el punto de partida de sus filosofías.

Aquí podría argüirse que el cogito no es solamente un acto, sino 
un acto consciente, y que por tanto en el punto de partida de la filosofía hay que admitir de alguna manera la conciencia. Ahora bien, el que el cogito sea consciente no prueba la existencia de "la" conciencia como una realidad subjetual, sustancial o de cualquier otro tipo. En el punto de partida de la filosofía tenemos ciertamente un acto, pero no "la" conciencia como una realidad. De hecho, todavía no sabemos si el cogito es siempre y necesariamente un acto consciente. Es frecuente hablar de actos inconsciente. En cualquier caso, de momento no sabemos qué es exactamente lo que constituye a un acto en acto consciente. Se trata de preguntas ulteriores que no podemos considerar como inmeditamente resueltas en el mismo momento en que hemos alcanzado el cogito. Pensar que con el cogito se nos da inexorable e inmediatamente "la" conciencia es un presupuesto no justificado en el punto de partida de la filosofía. Creer, además, que esta conciencia es un sujeto o una sustancia implica introducir en el punto de partida de la filosofía una concepción aristotélica de la realidad que no hemos justificado previamente.

Sin embargo, las razones del subjetivismo no están solamente en la herencia aristotélica. El problema es probablemente más radical, y está en la raíz tanto del aristotelismo clásico como del subjetivismo moderno. Lo que sucede es que las lenguas indoeuropeas entienden los actos, que expresan mediante un verbo, como "predicados" de lo que gramaticalmente se llama precisamente "sujeto". La estructura filosófica refleja una estructura gramatical. Dicho en otros términos: el cambio del cogito por el ego delata presupuestos hondamente incrustados en las estructuras lingüísticas indoeuropeas. Estos presupuestos no aparecen necesariamente en otras familias lingüísticas, en las cuales lo que nosotros llamamos "sujeto" puede funcionar, por ejemplo en las lenguas semíticas, como uno de los "predicados" del verbo, el cual es entonces el que encabeza la oración. En las raíces del subjetivismo moderno nos encontramos con lo Nietzsche consideraba "engaños de la gramática" o lo que la filosofía analítica llamaría una "enfermedad del lenguaje". Una auténtica filosofía primera tiene que liberarse de estos engaños y enfermedades para justificar radicalmente su propio punto de partida.

En el caso de Husserl hay otra razón para el deslizamiento des- 
de el acto hacia la subjetividad. Se trata de una razón más explícita y más característica de su proyecto filosófico. Husserl está buscando una evidencia apodíctica, y esta evidencia no se la pueden proporcionar los hechos, pues ellos son, a su modo de ver, algo contingente. Los actos que lleva a cabo la subjetividad son actos que ciertamente se han realizado, pero que podrían nunca haber sido ejecutados13. Justamente por ello no poseen necesidad apodíctica. En cambio, la subjetividad sí tiene para Husserl un carácter apodíctico. Husserl señala que, incluso si Dios hubiera destruido el mundo entero incluyéndome a mi mismo y todo lo que vemos no fuera más que pura apariencia, lo que sigue teniendo evidencia apodíctica es esa pura subjetividad para la cual todo es apariencia14. Mientras que los actos, en la concepción de Husserl, tienen un carácter contingente, la subjetividad goza de una evidencia apodíctica.

Naturalmente, puede discutirse si la experiencia de la subjetividad es tan apodíctica como Husserl pretende. Hume pensaría que en realidad no tengo ninguna experiencia de la subjetividad, sino solamente un torrente de impresiones sensibles 15 . Heidegger subrayará la autocomprensión del existente (Dasein) de su contingencia radical en cuanto "ser para la muerte" (Sein zum Tode)16. Enrique Dussel diría que esta pretendida apodicticidad ha surgido en virtud de una divinización de la subjetividad, que asume caracteres propios de Dios en cuanto ser necesario17. Nietzsche hubiera señalado que la exigencia de apodicticidad es propia de una filosofía que quiere escapar de la facticidad del devenir creando mundos ficticios a salvo de toda contingencia, los cuales constituyen en el fondo una calumnia de este mundo18. En realidad, todas estas críticas a la apodicticidad de la subjetividad tienen mucho de acertadas, pero en este momento solamente podemos hacerlas nuestras con algunos matices importantes.

Respecto a Hume hay que señalar que no se puede descartar algún tipo de percepción de la propia realidad. Esto no se puede excluir todavía en el punto de partida de la filosofía, pues requiere una reflexión más detenida. Lo único que afirmamos de momento es que este punto de partida no hay que buscarto en una presunta subietividad, sino en algo más cercano al acto que constituye cogito. Respecto a Heidegger hay que señalar que en el punto de partida 
de la filosofía no tenemos todavía la certeza de que hemos de morir. Esto requiere una experiencia vital más amplia que supera los límites del cogito. Respecto a Dussel hay que decir que, por mucho que la filosofía moderna haya absolutizado la subjetividad, en el punto de partida de la filosofía no tenemos todavía los fundamentos éticos o religiosos para criticar al sujeto de la filosofía moderna. Lo único que podemos decir es que el punto de partida de la filosofía no es una subjetividad. Finalmente, respecto a Nietzsche, hay que señalar que los motivos históricos, psicológicos o teológicos que han llevado a la búsqueda de la apodicticidad no aparecen todavía en el cogito.

Ahora bien, de todas las críticas mencionadas, la de Nietzsche es la más molesta de todas, porque no sólo apunta a los límites de Descartes o de Husserl, sino que niega la posibilidad de toda filosofía primera en cuanto búsqueda de la apodicticidad. En realidad, podríamos preguntanos si todo nuestro intento de buscar un punto de partida para la filosofía no obedece, en realidad, a la búsqueda de un refugio a salvo de la contingencia que el Cristianismo ha introducido en la idea griega de ser. Sin embargo, creo que se puede mostrar que esto no es así. El cogito como prima veritas no es algo que no pueda ser de otra manera. Dudo pero podría no dudar, pienso pero podría no pensar, amo pero podría no amar. El cogito no es una evidencia apodíctica que nos ponga a salvo de la contingencia. La huida de la contingencia es precisamente lo que ha llevado a Husserl a abandonar el cogito como acto para dirigirse a la subjetividad apodíctica. Pero en realidad, la verdad primera no es una subjetividad, sino un actó, y por tanto algo meramente fáctico El punto de partida que estamos buscando sería un acto modesto y radical.

\section{Los caracteres del comienzo}

$\Lambda$ hora bien, para explicar este punto de partida tenemos que Adecir qué es realmente eso que con toda vaguedad hemos denominado cogito. En segundo lugar, hemos de aclarar lo que entendemos por verdad primera a diferencia de la evidencia. $Y$, en tercer lugar, tenemos que aclarar qué es lo que llamamos facticidad a diferencia de la apodicticidad. Con esto habríamos comenzado la verdadera andadura de una filosofía primera. En ella procede- 
remos del modo más cuidadoso posible, intentando no añadir al acto del cogito nada que no esté presente en él. Por mucho que nuestro modo indoeuropeo de pensar exija, por ejemplo, un sujeto para este acto, no aceptaremos ese sujeto más que en la medida en que realmente aparezca en el acto mismo. Es decir, nos vamos a atener de momento a lo que inmediatamente encontramos en esa verdad primera, sin pretender abandonarla nunca hacia su posible fundamento en un sujeto, en un yo, en una sustancia, o en cualquier otra instancia que no se haya presentado en el acto primero del que no puedo dudar. La fundamentación de tal acto es una tarea distinta, que no compete a la filosofía primera como determinación del punto de partida del filosofar.

a) Para determinar qué es en realidad el cogito conviene comenzar señalando que éste, tal como lo entienden tanto Descartes como Husserl, no consiste solamente en lo que usualmente llamamos "pensar" en cuanto actividad de la razón. También el juzgar, querer, el sentir, el imaginar, el amar, el odiar, etc., entran en lo que ambos filósofos entienden por cogito19. En latín, el término cogito incluye en ocasiones la intención o el deseo. Sin embargo, tiene un sentido más cognoscitivo que afectivo o volitivo. Asimismo, cuando Descartes y Husserl nos dicen algo más concreto sobre el cogito tienden a privilegiar los aspectos intelectivos del mismo. Descartes, al estudiar los contenidos del cogito, se centra solamente en aquellos contenidos intelectivos que él llama "ideas"20. Del mismo modo, Husserl señala que, una vez realizada la reducción, la actitud en la que queda el sujeto es una actitud puramente teórica21. Esto ha llevado a que algún autor contemporáneo, incluso cuando subraya la prioridad del cogito como acto sobre el ego, asuma que el cogito consiste en pensar22.

Ahora bien, en el punto de partida de la filosofía no está justificado reducir el cogito a mero pensamiento. Por un lado, ese dudar del que no puedo dudar no es un acto puramente intelectivo. El dudar envuelve siempre momentos volitivos $y$ afectivos que no son puro pensar. Además, no se ve por qué el acto de pensar vaya a ser más primario que otros actos. La verdad primera, a salvo de todo cuestionamiento, no es solamente que estoy dudando, sino también que estoy sintiendo, queriendo, amando, imaginando, odiando, deseando, etc., al menos en la medida en que estos actos 
están siendo realizados. Pues bien, lo que tienen en común todos estos actos no es su carácter pensante, sino simplemente el que todos ellos son actos. En el punto de partida de la filosofía no podemos convertir a los actos volitivos o afectivos en sucedáneos de la intelección. Aquí no sirve la apelación a Zubiri para señalar que los actos afectivos y volitivos están inscritos en una "formalidad de realidad", la cual sería de carácter intelectivo. El concepto de "realidad" supone un análisis minucioso de los distintos tipos de actos para encontrar en todos ellos esa presunta formalidad. Pero, antes de llevar a cabo ese análisis, tenemos ya una verdad primera, que es el hecho de que dudar, sentir, amar, querer, imaginar, etc., son todos ellos simples actos. Esta es la verdad primaria de la que tenemos que partir.

Tenemos, por tanto, una pluralidad de actos. $Y$ tenemos el hecho de que siempre se trata de actos. Por eso, para calificar mejor nuestra verdad primaria, podemos decir sencillamente que ésta consiste en un ago. E1 cógito cartesiano, para ser librado de su unilateralidad intelectiva, ha de ser sustituido por un ago $\mathrm{El}$ ago es el verbo latino para "hacer". A diferencia del verbo facio, que tiende a designar la actividad productiva y eficiente, el ago tiene un significado más amplio e impreciso. Es algo semejante a la diferencia entre do y make en inglés o entre tun y machen en alemán. Digamos que el facio es un tipo de ago, mientras que el ago no es siempre un hacer eficiente. Todo acto en que estemos empeñados es un ago, y del participio pasivo de ago (actum) deriva justamente la palabra "acto". Pues bien, la verdad primera es el ago, lo que podríamos traducir simplemente como "hago" El punto de partida de la filosofía no es un cogito intelectualizado, sino simplemente un modesto ago, cuyas dimensiones fundamentales están todavía por analizar.

Naturalmente, tenemos que cuidarnos de pasar de este ago a un ego, a un "yo", entendido como sujeto o como sustancia. El punto de partida de la filosofía es un ago, y no un "yo" subjetual o sustancial. Tampoco podemos decir en este momento que el punto de partida de la filosofía está en una "cosa actuante" distinta de sus actos. Ciertamente, los agentes estamos de alguna manera implicados en nuestros actos. Pero todavía no sabemos de qué manera. Por tanto, para evitar los ya conocidos engaños del lenguaje, no 
podemos ahora afirmar apresuradamente la realidad de un sujeto, una sustancia o una cosa distinta de los actos mismos. En ellos hemos de permanecer para analizarlos exhaustivamente y ver en qué manera aparece en esos actos una dimensión personal. De momento es suficiente con que digamos "ago". Con eso indicamos que la verdad primera es un agere. Ahora bien, el acto del que no podemos dudar no es un agere impersonal sino un ago modulado personalmente. Por eso, sin prejuzgar en qué consiste esta modulación personal, y sin deslizarnos hacia el agente de tal acto, permanezcamos aferrados con firmeza a la radicalidad primera del ago.

Uno podría preguntarse por qué hemos optado por un ago en primera persona, y no por la segunda persona o por la tercera. También cabría comenzar por el plural en lugar del singular. Ahora bien, en el punto de partida del filosofar no podemos decidir todavía esta cuestión. Solamente un análisis más detallado de nuestros actos nos puede decir cómo aparecen en ellos el "yo", el "tú" o el "nosotros". De momento, el ago, a diferencia del agere, indica solamente el carácter personal de esos actos, sin decidir todavía sobre el singular o el plural, y sin decidir tampoco cuál de las personas es verdaderamente la primera. En el inicio de la filosofía primera tenemos solamente nuestros actos. Ciertamente, estos actos los analizamos utilizando un lenguaje. $Y$ esto indica ya que la filosofía primera no es una tarea solitaria, sino un esfuerzo colectivo, al menos en el sentido de comunicable. La filosofía primera se hace en una comunidad y en una lengua determinadas. Pero esto no significa que haya que sustituir el cogito por un "yo argumento en el discurso"23. Tanto el argumentar, como el sentir, el pensar o el amar son actos, y de momento no tenemos especiales razones para preferir los actos argumentativos.

En el punto de partida de la filosofía hemos de aceptar una pluralidad de actos y una indeterminación respecto a los actores que los realizan. Sin embargo, aquello de lo que no puedo dudar es un acto, y no un sujeto, una sustancia, o todo un lenguaje ya constituido. El lenguaje constituye un tema filosófico de primera magnitud. Sin embargo, el lenguaje en su totalidad no constituye una verdad primaria de la que podamos arrancar. Muchos aspectos del lenguaje solamente son accesibles mediante teorías lin- 
güísticas o fonéticas muy elaboradas. Sin embargo, hay algo en el lenguaje que sí nos está dado de un modo inmediato: es justamente el lenguaje en cuanto acto, en cuanto un ago. Pues bien, antes de deslizarnos al sujeto, a las estructuras lingüísticas del discurso, o a cualquier otra instancia teórica, aferrémonos a la verdad primera del ago, pues de ella resultarán insospechadas riquezas que nunca encontraremos si abandonamos precipitadamente el punto de partida del filosofar. Este abandono nos podrá colocar rápidamente, por ejemplo, en la intersubjetividad, pero nunca nos liberará de todos los presupuestos con los que ese concepto carga, incluyendo la idea misma de subjetividad.

Esto significa que, del mismo modo que prescindimos en este momento del agente del acto, hemos de prescindir también de querer conceptuar exhaustivamente su término. Es sabido que Husserl amplía el cogito de Descartes haciendo de él un cogito cogitatum ${ }^{24}$. Las cosas no son, para Husserl, meros contenidos ideales del cogito, sino su polo intencional. En nuestro caso hemos sustituido el cogito por un ago. Pero, ¿cuál es el término de este "hago"? No cabe duda de que podemos hacer muchas cosas. El hacer puede dirigirse hacia personas que pensamos, sentimos o imaginamos. Podemos pensar en números, en figuras geométricas o en personajes novelescos. Además, el acto mismo puede ser también, en cierto modo, el término de nuestros propios actos, cuando lo que pretendemos es solamente hacer algo por el acto mismo, sin perseguir un término. Por ejemplo, se puede bailar por el mero gusto de hacerlo. El término del ago pueden ser cosas, personas, números, ficciones o también los actos mismos. Por eso, en el punto de partida de la filosofía, lo único que podemos decir es que nuestro hacer es siempre un hacer "algo". Así como el ago tiene una dimensión personal, del mismo modo tiene también una dimensión "terminal". Por eso, el ago es siempre un ago aliquid. Naturalmente, análisis más minuciosos habrán de determinar en qué consiste ese aliquid y cómo se relaciona con el ago. De momento digamos simplemente que la verdad primera es un ago aliquid.

En definitiva, el ego cogito de la tradición cartesiana se nos ha transformado en un ago aliquid Es la primera verdad obtenida y ella constituye el punto de partida buscado. Ahora hemos de aclarar en qué consiste esa verdad primera. 
b) Hasta aquí hemos hablado simplemente de "verdad primera". Pero Descartes y Husserl nos dirían que a ellos no les interesan las verdades, sino las evidencias. En ambos pesa decisivamente el ideal de la matemática y de la lógica como modelo para la filosofía. Sin embargo, la idea de una "evidencia" contiene en sí cierta dualidad. En las ciencias exactas, se trata de la dualidad entre las premisas y la conclusión. Ahora bien, esto no es tan fácil de aplicar a la filosofía cuando estamos situados en el principio mismo del filosofar. En ese primer principio no tenemos todavía una dualidad. Cuando se dice "cogito, ergo sum" se está cometiendo un error formal. El ergo indica una conclusión lógica, que solamente sería correcta si tuviéramos una premisa mayor que afirme que "todo ser que piensa, existe". La premisa menor sería el "yo pienso". Y entonces podríamos obtener la conclusión "yo existo".

Sin embargo, no es ésta la mejor formulación del hallazgo cartesiano25. En el inicio del filosofar no disponemos de ninguna razón para aceptar la mencionada premisa mayor. Lo único que tiene Descartes es la verdad indubitable del cogito, y nada más. En nuestra perspectiva habría que decir que la primera verdad que tenemos es el ago, y no unat teoría sobre las realidades pensantes o existentes."La primera verdad no es la evidencia de un razonamiento concluyente. Se podría pensar entonces en otro tipo de evidencia: la evidencia con la que el ago se impone a nuestra inteligencia. Husserl ha hablado, en este contexto, de la evidencia como una "realización" (Erfüllung). Tendríamos evidencia cuando las cosas dadas se realizan en el sentido (Sinngehalt) que ellas tienen para nosotros 26 . Zubiri, por su parte, ha hablado de la evidencia como "exigencia" de la cosa respecto a nuestras ideas (en el sentido más amplio del término "idea")27. En ambos casos, la evidencia entraña una dualidad entre aquello que inteligimos y las ideas desde los cuáles es inteligido y que constituyen su sentido. Hay ideas que se "realizan" con evidencia en las cosas, y hay que cosas que "exigen" que las concibamos con determinadas ideas.

La evidencia, por tanto, es siempre la evidencia de algo respecto a unas determinadas ideas desde las cuales inteligimos su sentido. Pero esto plantea un grave problema, porque estas ideas son enormemente variables según las lenguas y las culturas. Para nosotros es evidente que este papel se presenta a nuestra inteligencia 
como blanco. Para un esquimal, esta evidencia no se da respecto de nuestro "blanco", sino respecto de uno de los muchos conceptos con los que en su lengua se denomina lo que nosotros simplemente llamamos blanco. Puede ser que el acto como acto sea algo indubitable. Pero los conceptos con los que analizaremos este ago son conceptos tomados de nuestra lengua, de nuestra cultura, de las ciencias en su estadio actual, de la historia de la filosofía, etc. $Y$, por tanto, por mucho que nuestro análisis obtenga resultados evidentes, esta evidencia será siempre relativa a un determinado sistema de conceptos que hemos empleado. En nuestra lengua es evidente que este papel es blanco, porque en él se realiza el sentido de lo blanco (Husserl) o porque él exige, entre nuestros conceptos para colores, que lo intelijamos como blanco (Zubiri). La evidencia es siempre relativa a un sistema de ideas.

Para superar esta dualidad entre lo que queremos inteligir y los distintos sistemas de ideas, Zubiri ha propuesto hablar de "verdad real" 28 . La verdad real no sería relativa a ningún sistema de ideas. Ella consistiría, como diría Zubiri, en la mera actualidad de la cosa real en la aprehensión. En este puro estar presente de la cosa no se nos presenta el problema de la relatividad de toda intelección de la cosa a nuestras ideas, justamente porque todavía no estamos analizando la cosa, conceptuándola, determinando su sentido, etc. Solamente tenemos la cosa en nuestra aprehensión, y nada más. De este modo, el ago sería algo simplemente actualizado, y no algo "evidente". La verdad del ago sería una verdad real. En ella no habría posibilidad de error, porque los errores comienzan a la hora de analizar el ago en una determinada lengua, cultura, etc. En este análisis tendremos, sin duda, evidencias. Y estas evidencias son todas ellas mejorables si enriquecemos nuestro sistema de ideas. Pero el ago, antes de toda evidencia, sería una verdad real. De ahí su valor como punto de partida de la filosofía. Este punto de partida sería más radical que una evidencia y en él no cabría error ni desviación. Los errores y desviaciones comenzarían ulteriormente, al analizar esta verdad real.

Ahora bien, la verdad real implica todavía una dualidad entre la cosa que se actualiza y la aprehensión en la que se actualiza. Pero el ago no lo hemos tomado en cuanto actualizado en la aprehensión, sino en cuanto acto, como es acto la aprehensión misma. 
Ya la aprehensión es un ago, con independencia de como este ago se actualice en una ulterior aprehensión. No estamos tratando aquí de la actualización en nuestra aprehensión de los actos de pensar, sentir, querer, desear, percibir, aprehender, amar, odiar, etc. Estamos tratando simplemente de esos actos, y nada más. Cuando hago algo, ese hacer es ya un factum primario, independientemente de cómo lo intelija. En la verdad real hay dualidad, mientras que el acto "hecho" es un mero factum en el que no cabe dualidad alguna. La equivalencia de Vico entre el verum y el factum, enunciada en otro contexto, apunta a lo que queremos señalar aquí. El factum, es decir el acto "hecho", es el verum primario, anterior a toda dualidad entre lo inteligido y la inteligencia. Es decir, si se quiere hablar de verdad, habría que decir que el ago constituye un verum radical, que no es la verdad de su aprehensión por la inteligencia, sino la "verdad simple" de su ejecución. Antes de toda verdad real está la verdad simple, y la verdad simple no es otra cosa que un factum. El factum de los actos "hechos" es la verdad primera que constituye nuestro punto de partida.

Podría pensarse que con este factum estamos aludiendo aquí a lo que Zubiri denomina "realidad". Antes de la verdad real como actualidad de la cosa en la intelección, estaría la realidad misma de esa cosa. Es interesante observar que, cuando Zubiri somete a crítica al punto de partida cartesiano, señala que Descartes ha atendido solamente a la verdad del cogito, no a su realidad. El pensamiento, antes de tener una verdad, es algo real29. Y la realidad, tal como la entiende Zubiri, es la formalidad con la que se inteligen las cosas cuando se actualizan en la aprehensión. Sin embargo, en nuestro planteamiento no nos estamos referiendo a la realidad con que se intelige el acto, sino al acto mismo en su simplicidad. Este acto se inteligirá con realidad y con verdad real, y ulteriormente se conceptuará con evidencia. Pero antes de toda intelección y de toda conceptuación, tenemos simplemente nuestros actos. El acto mismo de intelección, aunque se intelija como real, es un acto entre otros, con independencia del modo como lo intelijamos. Nuestros actos pueden ser todo lo reales, verdaderos y evidentes que se quiera. Pero son primariamente actos, y esa es el verum primario del que partimos. Es algo más radical que la realidad de Zubiri.

Ciertamente, esta idea de la verdad primera como "verdad sim- 
ple" difiere de los conceptos usuales de verdad, que suelen incluir una dualidad, aunque sea mínima, entre la cosa y la inteligencia. Aunque se apele al concepto semítico de verdad como seguridad y confianza, también ahí nos encontramos con una dualidad entre la cosa que se confía y la inteligencia que confía. Aquí hablamos de una verdad que es más radical que toda verdad en el sentido clásico del término porque no contiene ninguna dualidad. Es el acto mismo en cuanto raíz de toda realidad, de toda verdad real y de toda evidencia. Tal vez se podría aludir, a la idea de verdad que aparece en el náhuatl. En esta lengua, el concepto de verdad (nelli) parece estar emparentado con nelhuayotl, que significa justamente raíz, principio, fundamento, o base 30 . En cualquier caso, la etimología solamente es, en nuestro caso, un apoyo para señalar que el arkhé o principio del que partimos no es una verdad en el sentido clásico, sino el ago mismo en cuanto factum primario y "radical". El acto será real, será verdadero, será evidente, pero primaria y radicalmente es un acto.

Naturalmente, el análisis de estos actos requiere de ideas, y ahí aparecerán las evidencias respecto a los sistemas conceptuales que utilicemos. $Y$ aparecerán también las desviaciones y los errores. Sin embargo, cabe una precisión cada vez mayor en el análisis. $Y$ cabe también un perfeccionamiento creciente en el sistema conceptual utilizado, introduciendo nuevos conceptos y eliminando los presupuestos no cuestionados. Las evidencias no constituyen un sistema cerrado, sino un campo abierto a ulteriores radicalizaciones. Del mismo modo en que el ago radicaliza el ego cogito, nuestros análisis podrán ser también radicalizados ulteriormente. Ciertamente, el ago es un verum simple, un factum, pero la conceptuación de este factum es algo que está abierto a ulteriores radicalizaciones. Aunque estas radicalizaciones ulteriores serán siempre actos, la conceptuación de los mismos es una tarea abierta. La filosofía primera es una tarea que nunca se puede dar por definitivamente concluida. La historia de la filosofía, contra lo que Hegel pretendía, no puede clausurarse.

c) La prima veritas de la filosofía no es una evidencia, ni una verdad real, ni siquiera una realidad, sino un factum, todo lo real, verdadero y evidente que se quiera. Pues bien, este factum tiene una firmeza primaria, que no es la firmeza de lo real ni la firmeza 
de lo verdadero, sino la firmeza de unos actos. No se trata de que nuestros actos sean muy contundentes. También el dudar, el titubear y el vacilar son firmes como actos, aunque no sean actos contundentes. Es la firmeza de lo factum, que como algo "hecho" no ofrece error ni permite la duda. Estamos ante la firmeza del acto en cuanto acto, antes de toda conceptuación del mismo. Cuando pienso, cuando amo, cuando quiero, cuando vacilo, puedo hacer todo esto con mayor o menor contundencia. Pero en el vacilar mismo como hecho no hay duda, ni error, ni dualidad: simplemente vacilo. Es un hecho que nada en el mundo puede destruir ya como hecho: he vacilado. El actum es un factum: el ago es un hecho indestructible e indubitable. Es lo hecho.

Este hecho firme es un hecho radical. Y lo es porque todas las percepciones de lo real, todas las verdades y todas las evidencias ulteriores se fundan en él. Toda percepción de cosas reales, toda intelección de los mismos, toda correspondencia evidente entre lo percibido y nuestros conceptos, presupone siempre el factum de nuestros actos, incluyento nuestros actos perceptivos o intelectivos. Naturalmente, toda evidencia es radicalizable en la historia de la filosofía. Pero lo radical por excelencia es el ago mismo como acto. Su conceptuación en el análisis puede mejorar, pero esta conceptuación será siempre un acto. El ago como hecho no es algo mejorable. Los hechos mismos, en su carácter de hechos, no admiten ya alteración. Por eso constituyen el comienzo radical del saber. Toda filosofía y toda ciencia es, antes que nada, un factum, en este caso concreto, un factum intelectivo. Y este hecho es el presupuesto de toda su realidad y de toda su verdad. Por eso mismo, el ago constituye el comienzo firme y radical que estábamos buscando como punto de partida del filosofar.

Ahora bien, estamos hablando del ago como un hecho. Y Husserl ha insistido en que de los hechos no se sigue ninguna verdad apodíctica. Los hechos son así, pero pudieron haber sido de otra manera. Su firmeza y radicalidad no entraña necesidad apodíctica. $Y$ hemos visto que la exigencia de una necesidad apodíctica puede venir de la búsqueda de un refugio seguro a salvo de toda negatividad. Ahora bien, el que los actos puedan no haber sido realizados, no significa que estén afectados de algún modo por la negatividad. Esto es una afirmación metafísica que desborda el 
punto de partida de la filosofía. En este punto de partida tenemos solamente los actos, y sobre ellos no tenemos por qué proyectar la estructura de nuestro lenguaje. En el lenguaje hay ciertamente negaciones. Pero en los actos mismos no hay negación. Sólo de un modo metafórico se puede decir que los actos son negativos, en el sentido de que pueden ser, por ejemplo, éticamente reprobables. Pero, en sentido estricto, tanto la negación de bondad como la afirmación de maldad son propias de nuestros juicios éticos, y no de los actos mismos.

Por otra parte, la exigencia de necesidad apodíctica puede reflejar, como vimos, un influjo sobre la filosofía primera de la idea judeocristiana de creación, expresada en las categorías ontológicas griegas: las cosas creadas son, pero podrían no ser. Sin embargo, en el punto de partida de la filosofía no es posible asumir la concepción cristiana del ser como ser creado y, por tanto, contingente. Por eso no tiene mucho sentido la búsqueda de un refugio a salvo de lo contingente. Ahora bien, en el punto de partida de la filosofía tampoco se puede decir que los hechos constituyan algo contingente en el sentido de una contingencia creacional. Ciertamente, podemos decir que los actos son contingentes en el sentido de que los actos se han ejecutado, pero podrían no haberse realizado nunca. Esto es algo que podemos decir de muchos y, tal vez, de todos nuestros actos. Se trata de una contingencia más legítima desde el punto de vista del análisis de nuestros actos, porque no supone toda una teología. En este sentido podríamos entonces decir que los actos no constituyen evidencias apodícticas, sino hechos contingentes.

Ahora bien, en el primer estudio del ago no tenemos todavía la consideración sobre otros actos posibles. Esto requiere un análisis más minucioso de nuestros actos y de sus posibilidades. Estudiar en qué casos un acto podría no haber tenido lugar es algo que no pertenece a la verdad primera del ago. En el punto de partida de la filosofía tenemos simplemente el factum del acto realizado. Por eso hay que decir que, en sentido estricto, el ago no es algo apodíctico ni algo contingente. Simplemente, el acto ha tenido lugar, independientemente de la pregunta por si hubiera podido ser de otra manera. Si se admite la redundancia, habría que decir que se trata de un hecho fáctico. Aquí lo fáctico no desgina lo contingente, 
sino lo simplemente "facto", lo simplemente "hecho". La facticidad se aplica a lo que no es apodícticamente necesario, pero cuya contingencia no ha sido aún determinada. Es un simple hecho, y nada más. El estudio de su contingencia respecto a otros posibles actos constituye una cuestión ulterior. En el comienzo de la filosofía tenemos un hecho fáctico, y no una evidencia apodíctica. No hemos huido de la facticidad del devenir para refugiarnos en el reino de lo apodíctico, sino que estamos en el centro mismo de la facticidad: en el ago.

\section{Conclusión}

F $\mathrm{n}$ definitiva podemos concluir que el tema de la filosofía priL mera no es una metafísica del ser, como pensaría Aristóteles, pero tampoco una descripción de las evidencias apodícticas de la subjetividad. La filosofía primera, en cuanto comienzo radical del filosofar, es un análisis del ago como un factum fáctico. La filosofía primera es, por ello, una filosofía eminentemente práctica. Se podría pensar que con esto estamos de algún modo aludiendo a ciertas interpretaciones del marxismo como filosofía de la praxis 31 , o a la idea de Maurice Blondel de una filosofía de la acción como punto de partida del filosofar 32 . Naturalmente, puede haber en nuestro planteamiento obvias convergencias con otros autores. Sin embargo, no hemos partido escolásticamente de Marx, ni de Blondel, ni de otros filósofos, sino que nos hemos entregado a la búsqueda filosófica de un primer principio que esté libre de toda duda sobre posibles presupuestos no justificados. Tampoco hemos llegado al ago en virtud de un intento por superar la separación secular entre la teoría y la práctica, sino simplemente como resultado de la búsqueda de un principio radical para el filosofar.

Se trata, por tanto, solamente de convergencias con otros planteamientos, no de un seguimiento escolar de los mismos. Y las convergencias no se acabar aquí. Aristóteles nos dice que la novedad de Sócrates fue su análisis de la práctica humana, buscando en ella lo universal33. Husserl ha admirado en Sócrates su radicalidad práctica como respuesta al escepticismo sofista, pero considera que la verdadera radicalidad teórica, heredera sin duda de la radicalidad socrática, comienza verdaderamente con Platón ${ }^{34}$. En realidad, Husserl no podría concebir nunca una filosofía pri- 
mera que comience con algo tan fáctico como nuestros actos. Sin embargo, nuestra radicalización filosófica nos ha conducido de nuevo a una situación socrática: nos ha puesto ante los actos y nos ha descubierto que ellos constituyen el punto de partida de la filosofía, el tema de una auténtica filosofía primera.

Tanto Platón como Aristóteles, buscando lo universal, abandonan los actos para dirigirse al mundo de las ideas o al de las sustancias. Con ello se perdió el núcleo del legado socrático. Cuando el oráculo de Delfos le comunica a Sócrates el famoso "conócete a ti mismo", para el filósofo esto no significaba el imperativo de estudiar su propia subjetividad, sino la tarea de enfrentarse filosóficamente con las acciones humanas. Este estudio de las acciones humanas implicaba para Sócrates no sólo rechazar el escepticismo teórico de la sofística, sino también el escepticismo práctico que representa el hecho de la injusticia. Por eso, la filosofía de Sócrates es una filosofía eminentemente ética y política. $Y$ con ello descubrimos una convergencia, en nuestro punto de partida, no sólo con lo que probablemente fueron las intenciones originarias del socratismo, sino también con lo que se ha llamado, en años recientes, la "filosofía de la liberación". En su contexto se ha planteado explícitamente la tesis de que la filosofía primera no es la metafísica del ser o de la subjetividad, sino la filosofía política entendida como filosofía de la acción 35 .

Sin embargo, no partimos aquí de ninguna escuela de filosofía de la liberación, ni tampoco de las escuelas en las que se inspira esa filosofía. Tampoco hemos arrancado de otras tradiciones filosóficas, como la pragmatista, con la que se podría señalar algunas convergencias o similitudes. Nos encontramos simplemente ante la pura facticidad de nuestros actos. A ellos hemos llegado como buscadores de un punto de partida radical para el filosofar. Ahora bien, estos actos han de ser sometidos a análisis más detallado. La filosofía primera no puede contentarse con detectar el punto de partida del filosofar. Tiene también que llevar a cabo un análisis del mismo lo más completo posible. Es algo que sobrepasa los límites de estas páginas. Sin embargo, el desarrollo de este análisis es esencial para aclarar algunos puntos fundamentales que aquí han quedado pendientes, como es la cuestión de los agentes del ago y del aliquid como su término. Pero, además, solamente la rea- 
lización de ese análisis podrá mostrar de un modo sistemático los parecidos y diferencias con esas filosofías que, de algún modo, convergen en nuestro planteamiento. Estamos pues ante una tarea abierta.

\section{Notas}

1. Cf. H. G. Gadamer, Wahrheit und Methode. Ergänzungen, Tubinga, 1986, pp. 77-91.

2. Entre la creciente bibliografía sobre el problema puede verse el libro, ya clásico, de L. Zea, sobre La filosofía americana como filosofía sin más, México, 1980 (T ed.).

3. Luis Villoro decía que "El punto de arranque de una tradición filosofica no está en la especificidad o peculiaridad de un pensamiento, sino en la fuerza y hondura de su reflexión crítica", citado en L. Zea, La filosofia latinoamericana como filosofía sin más, op. cit., p. 66.

4. Es una vía ya practicada por Hegel, y que apunta en sus primeros escritos como síntesis de naturaleza y subjetividad, cf. G. W. F. Hegel, "Differenz des Fichteschen und Schllingschen Systems der Philosophie", en Werke, vol. 2, Francfort, 1970, pp. 9-138. Una vía semejante para justificar una concepción de la filosofía primera como filosofia en la acción puede verse en mi trabajo sobre "El hombre en el horizonte de la praxis", en ECA $459-460$ (1987) 57-87.

5. Se puede señalar que en los últimos escritos de $X$. Zubiri aparece un planteamiento de este tipo, cf. Inteligencia sentiente. Inteligencia y realidad, Madrid, 1984 (34 ed.), pp. 171ss.

6. Cf. R. Descartes, Méditations touchant la première philosophie, en sus Oeuvres et lettres, Brujas, 1952; E. Husserl, Erste Philosophie, vol. 1, La Haya, 1956.

7. Una crítica especialmente aguda al cogito la encontramos en F. Nietzsche, Jenseits wn Gut und Böse, en su Kritische Studienausgabe, Berlín, 1988 (2* ed.), vol. 5, pp. 31, 73; cf. también los Nachgelassene Fragmente 1884-1885, en su Kritische Studienausgabe, op. cit., vol. 11, pp. 637-639.

8. Una crítica del ego cartesiano desde la perspectiva de la filosofía de la liberación puede verse en E. Dussel, Introducción a la filosofia de la liberación, México, 1977 , p. $110-111$.

9. Cf. J. Habermas, "Erkenntnis und Interesse", en Technik und Wissenschaft als Ideologie, Francfort, 1968, pp. 152ss.

10. Cf. E. Husserl, Die Krisis der europäischen Wissenschaften und die transzendentale Phänomenologie, La Haya, 1976, pp. 1-17.

11. Cf. R. Descartes, Méditations touchant la première philosophie, op. cit., Med. II, p. 276. y Med. III, p. 293.

12. Cf. E. Husserl, Erste Philosophie, vol. 1, op. cit., p. 163.

13. Cf. E. Husserl, Erste Philosophie, vol. 2, La Haya, 1959, pp. 50,

14. Cf. ibid., p. 73.

15. Cf. D. Hume, A Treatise of Human Nature (ed. por L. A. Selby-Bigge), Oxford, 1967, pp. 251-263. 
16. Cf. M. Heidegger, Sein und Zeit, Tubinga, 1986 (16“ ed.), PP. 252ss.

17. Cf. E. Dussel, Introducción a la filosofia de la liberación, op. cit., p. 110.

18. Cf. F. Nietzsche, Nachgelassene Fragmente 1887-1889, en su Kritische Studienausgabe, op. cit., vol. 13, pp. 336-337.

19. Cf. R. Descartes, Méditations touchant la première philosophie, op. cit., Med. II, p. 278; E. Husserl, Erste Philosophie, vol. 2, op. cit., PP. 82, 23.

20. Cf. R. Descartes, Méditations touchant la premiète philosophie, op. cil., Med. III, PP. 284-287.

21. Cf. E. Husserl, Erste Philosophie, vol. 2, op. cit., p. 106.

22. Cf. E. Le Roy, Essai d'une philosophie première. L'exigence idealiste et l'exigence morale, vol. 1, París, 1956, Pp. 232-233.

23. Cf. K. - O. Apel, "A ética do discurso em face do desafio da filosofia da libertação latino-americana", en A. Sidekum (ed.), Ético do discurso e filosofia da libertação. Modelos complementares, San Leopoldo, 1994, p. 24.

24. Cf. E. Husserl, Cartesianische Medilationen, Hamburgo, 1987, p. 34.

25. Mientras que en el Discours de la méthode Descartes utiliza una formula deductiva (je pense, donc je suis, cf. Ouvres et lettres, op. cit., P. 148), en las Méditations la formulación es unitaria (je suis, j'eriste, cf. Ouvres et lettres, op. cit., p. 277).

26. Cf. E. Husserl, Erste Philosophie, vol. 2, op. cit., p. 33.

27. Cf. X. Zubiri, Inteligencia y logos, Madrid, 1982, pp. 212-252.

28. Cf. $X$. Zubiri, Inteligencia sentiente. Inteligencia y realidad, op. cit., pp. 229-238.

29. Cf. X. Zubiri, Los problemas fundamentales de la melafísica occidental, Madrid, 1994, pp. 133-134.

30. Cf. M. León-Portilla, La filosofia náhuatl estudiada en sus fuentes, México, 1966, p. 140.

31. Cf. A. Gramsci, Quaderni del carcere, vol. 2, Turín, 1975, pp. 1375-1509; A. Sánchez Vázquez, Filosofía de la praxis, México, 1980 (4 ed.).

32. Cf. M. Blondel, El punto de partida de la investigación filosófica, Barcelona, 1967.

33. Cf. Aristóteles, Metafísica, I $6987 \mathrm{~b}$; XIII $41078 \mathrm{~b}$.

34. Cf. E. Husserl, Erste Philosophie, vol. 1, op. cit., pp. 11-12.

35. Cf. R. Fornet-Betancourt, Estudios de filosofia latinoamericana, México, 1992, Pp. 47-48. 